\title{
Evaluating Knowledge, Practices, and Barriers of Paediatric Pain Management among Nurses in a Tertiary Health Facility in the Northern Region of Ghana: A Descriptive Cross-Sectional Study
}

\author{
Abubakari Wuni (D), ${ }^{1}$ Solomon Mohammed Salia, ${ }^{2}$ Mudasir Mohammed Ibrahim (D),

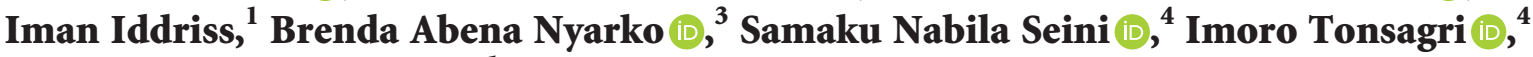 \\ and Jauharatu Mohammed ${ }^{1}$ \\ ${ }^{1}$ Nurses and Midwives Training College, P.O. Box 565, Tamale, Ghana \\ ${ }^{2}$ Department of Nursing, School of Nursing and Midwifery, University of Health and Allied Sciences, Ho, Ghana \\ ${ }^{3}$ Xiangya Nursing School, Central South University, Yuelu District, Changsha, Hunan, China \\ ${ }^{4}$ Tamale Teaching Hospital, Tamale, Ghana
}

Correspondence should be addressed to Abubakari Wuni; ibnkoomson@yahoo.com

Received 30 August 2020; Accepted 17 November 2020; Published 30 November 2020

Academic Editor: Marco Carotenuto

Copyright (c) 2020 Abubakari Wuni et al. This is an open access article distributed under the Creative Commons Attribution License, which permits unrestricted use, distribution, and reproduction in any medium, provided the original work is properly cited.

\begin{abstract}
Background. Pain is a major source of distress for children on admission, parents, and clinician. Hospitalized children continuously experience unrelieved pain; hence, the provision of effective pain management is an integral and important part of the nurse's role. Adequate knowledge and positive practices of nurses regarding pain management among children are key if optimal pain management is to be achieved among paediatric cases. However, there is a paucity of published data on paediatric management among nurses in the northern part of Ghana. Aim. The current study, therefore, evaluated nurse's knowledge and practices and identified the barriers to paediatric pain management in the Tamale Teaching Hospital, Ghana. Methodology. This was a descriptive cross-sectional facility-based study that employed a quantitative approach to data collection. A total of 180 nurses were selected conveniently from 10 selected wards of the hospital for the study. Data were collected using a questionnaire. The data were subsequently analyzed using the Statistical Package for Social Sciences version 23.0. Logistic regression analysis was done to determine the association between the dependent and independent variables of interest. Results. The findings revealed that the majority $(61.1 \%)$ of all the nurses had an overall good knowledge of paediatric pain management while $57.8 \%$ demonstrated good practices of pain management. From the study, the most reported barriers to paediatric pain management by the nurses were insufficient knowledge in pain management (76.1\%), inadequate paediatric pain assessment tools $(73.9 \%)$, and inadequate staffing $(72.2 \%)$. In further analysis, critical care nurses were 5.87 times more likely to engage in good practices of paediatric pain management than paediatric nurses ( $\mathrm{OR}=5.87$ (95\% CI: 1.07-32.00), $p=0.041)$. Conclusion . The majority (61.1\%) of all the respondents showed good knowledge of pain management and 57.8\% demonstrated good pain management practices. Despite the high knowledge and practice, factors such as insufficient knowledge in pain management (76.1\%), inadequate paediatric pain assessment tools (73.9\%), and inadequate nurse staffing (72.2\%) affect effective pain management. Paediatric pain management should be treated as a priority, and hence more efforts should be put in place to curtail the barriers that hinder its practice.
\end{abstract}

\section{Introduction}

Pain is a major source of distress for children on admission, parents, and clinicians [1]. Hospitalized children continuously experience unrelieved pain; hence, the provision of effective pain management is an integral and important part of the nurse's role [2]. The International Association for the Study of Pain (2011) defines pain as an 
unpleasant sensory and emotional experience from actual or potential tissue damage or described in terms of such damage. The effects of untreated or poorly managed children's pain cannot be overemphasized. Aside from the short-term biopsychosocial-developmental effects it has on the child, it can also lead to impaired pain sensitivity and long-lasting pain which is expensive to treat [3].

Clinical nurses play a vital role in managing children's pain and their accurate assessment and management of pain are necessary for positive patient outcomes [4].

However, despite the existence of protocols for effective pain control, paediatric pain is still high in children and the use of analgesics is usually inadequate [5-7].

Unrelieved pain in children may impose several unwanted physiological and psychosocial outcomes that can affect the child immediately and later in life, for instance, through increased sensitivity to later pain events [8].

Globally, studies revealed high rates of pain in hospitalized children who did not receive adequate pain management despite the increase of available treatments [9]. This seems to be the effect of inadequate knowledge of health professionals on the assessment and management of pain, as well as the presence of prejudices and barriers surrounding pain-relieving drugs [10]. Nurses per their training are often expected to have a good knowledge of pain management. However, studies showed that some nurses working with children have poor knowledge and practices with regard to paediatric pain management $[2,11,12]$. Studies by Aziato and Adejumo [13] revealed that nurses' inadequate pain management knowledge might have resulted from numerous causes such as curriculum gaps during training, inadequate clinical supervision, and lack of funding for organizing regular workshops.

Nonetheless, several other hindrances prevent nurses from optimally managing children's pain. A cross-sectional study of nurses conducted in the United States revealed deficient medication orders by physicians, inappropriate timing of premedication, low prioritization of pain management, and delays in analgesic availability as barriers to pain management [14]. Also, another study by Twycross and Collins [15] in the United Kingdom revealed a shortage of staff, a huge workload, inadequate knowledge, and shortages of pain medication as the nursing-related barriers to optimal pain care in children. Findings from Anim-Boamah [16] and Kusi Amponsah et al. [3] in the coastal part of Ghana showed that nurses had limited knowledge about pain assessment scales and pharmacological approaches for managing invasive procedural pain. The study also identified issues of communication difficulties in assessing and many other barriers to paediatric pain management.

Several studies have assessed the level of knowledge, practices, and barriers to paediatric pain management among nurses; however, there are limited studies conducted in developing countries and Ghana is no exception. Though few studies exist on paediatric pain management in the southern part of Ghana $[3,13,16]$, the same cannot be said about the northern part of Ghana. There is therefore the need to conduct a study on paediatric pain management in this part of the country. Therefore, this study sought to evaluate the level of knowledge, practices, and barriers to paediatric pain management among nurses in Tamale Teaching Hospital (TTH).

\section{Materials and Methods}

2.1. Study Design. The study employed a descriptive crosssectional design to assess the level of knowledge, pain management practices, and barriers to pain management among nurses at the TTH.

2.2. Setting. The study was carried out at the TTH which is located in the Tamale metropolis. The hospital is the largest health facility (800-bed capacity) in the northern region and serves as the only tertiary referral facility for Savana, North Eastern, Upper West, and Upper East regions, and neighboring Burkina Faso. The Tamale Metropolitan Assembly was established by a legislative instrument (LI 2068) and was subsequently elevated from Municipal Assembly into a Metropolis in 2004 with Tamale as the capital.

The hospital offers a wide range of general and specialist services. Data were collected from 10 selected wards of the hospital because these wards in one way or the other take care of children's conditions. These units were classified into paediatric units and nonpaediatric units. The paediatric units consisted of the main children's ward, the children's emergency ward, and the Neonatal Intensive Care Unit (NICU). The nonpaediatric wards included wards that nursed both adults and children and included general surgical ward, ENT ward, neurosurgical ward, plastic surgery, intensive care unit, orthopedic ward, and the main theatre recovery.

2.3. Study Population. The study targeted nurses working in the wards classified as paediatric and nonpaediatric units. 326 were actively engaged in nursing practice at the time of the study.

2.4. Inclusion and Exclusion Criteria. The study included all cadre of nurses who render clinical nursing care to children in the selected wards and who also consented to the study. The study on the other hand excluded student nurses and nurses undertaking national service as these nurses may be deemed inexperienced regarding paediatric pain management. Also, the study excluded all nurses who were on either study leave or annual leave.

\subsection{Sampling Method and Sample Size Determination.}

The sample required for the study was calculated using Yammane's [17] formula for calculating sample size based on the known population. A total sample size of 180 was determined. A convenient sampling strategy was employed in selecting the nurse to participate in the study.

2.6. Data Collection Tool. A structured questionnaire was used for data collection regarding nurses' knowledge, practices, and barriers to pain management. The 
questionnaire was made up of only closed-ended questions. The tool was carefully designed, taking note of pertinent literature available and the study objectives. The tool was structured into sections: section A: demographic characteristics of nurses; section B: knowledge on paediatric pain management with 11 items; section C: pain management practices made up of 12 items; section D: barriers to paediatric pain management with 9 items. The questionnaires were serially numbered to allow for easy entry into the dataset and analysis.

2.7. Data Collection Procedure. Collection of data commenced after gaining approval from the Research and Development Unit of Tamale Teaching Hospital. The data collection started in October 2019 and ended in December 2019. The questionnaires were administered to nurses in the respective wards after informed consent was obtained both verbally and written. The completed questionnaires were checked for completeness and consistency of the responses and kept in a sealed envelope. Each questionnaire was coded with an identification number before giving it to the respondents for easy identification. The questionnaires were self-administered individually and clarification was however given to nurses who needed further understanding of the questions.

2.8. Validity and Reliability. To ensure content and face validity, the questionnaire went through peer review among 8 experts in paediatrics consisting of nurses, lecturers, and doctors. Again, the questionnaire was pretested at Tamale West Hospital among 10 nurses using the same inclusion and exclusion criteria to measure accuracy and consistency. The pretesting did not detect any ambiguities in the questions so the original form of the questionnaire was maintained.

2.9. Data Analysis. The data collected were subsequently entered into Microsoft Excel for cleansing and then exported to Statistical Package for Social Sciences (SPSS version 23.0.). The data were presented in the form of tables and bar charts. Numerical data were presented in frequencies and percentages. In the classification of knowledge and practices, the mean was used as a reference point. Those nurses who scored below the knowledge mean score of 5.12 were classified as having poor knowledge while those who scored above were classified as having good knowledge of pain management. Again, the nurses who scored below the practice mean score of 10.28 were classified as having poor management practice, and nurses who scored above were classified as having a good practice.

Chi-square analysis was performed to ascertain the association between knowledge, pain management practices, and sociodemographic characteristics, and other factors and $p$ values of lesser than 0.05 were considered as statistically significant. Logistic regression analysis was also done to determine the relationship between independent and dependent factors at a confidence interval of $95 \%$.

2.10. Ethical Considerations. Ethical approval was attained from the Tamale Teaching Hospital Research and Development unit with an official reference number: TTH/R\&D/ SR/126. Additional permission was obtained from the ward managers of the selected wards, and written informed consent was obtained from the nurses before administering the questionnaire to them. The respondents were properly informed and guaranteed confidentiality and anonymity throughout the study and informed that the data collection process will be done on an individual basis to ensure their privacy.

\section{Results}

3.1. Sociodemographic Characteristics of Respondents. Table 1 illustrates the sociodemographic descriptions of the nurses. Of the 180 nurses who took part in the study, a little above $50 \%$ (52.8\%) were males and $46.1 \%$ were aged $26-30$ years. The majority $(82.2 \%)$ were general nurse category while only $6.1 \%$ were paediatric nurses. Less than $50 \%$ (44.4\%) were within the staff nurse category while the majority (64.4\%) were diploma holders.

3.2. Knowledge of Paediatric Pain Management. Only $15.6 \%$ of the nurses knew that children may sleep despite severe pain, and only $40.6 \%$ knew that young infants less than 6 months could tolerate opioids for pain relief. A majority $(65.0 \%)$ of participants indicated wrongly that vital signs are always reliable indicators of the intensity of a child's pain while $61.7 \%$ indicated that the intravenous route is the recommended route for administering opioid analgesics in children. Furthermore, $71.7 \%$ indicated wrongly that behavioral observation scales are the most reliable measures of assessing pain and sedation in intubated/ventilated children. Nurses' knowledge of paediatric pain management is illustrated in Table 2 .

3.3. Summary of Nurses' Knowledge on Paediatric Pain Management. In this study, knowledge was classified into good and poor. The study revealed that the majority (61.1\%) demonstrated good knowledge while $38.9 \%$ had poor knowledge with regard to paediatric pain management as shown in Figure 1.

3.4. Summary of Nurses' Knowledge of Paediatric Pain Management with regard to Ward of Practice or Work. The study further revealed that nurses who worked in the paediatric wards had a higher knowledge score (41.2\%) than those who worked in nonpaediatric wards $(36.8 \%)$. This is illustrated in Figure 2.

3.5. Association between Knowledge and Sociodemographic Characteristics. Table 3 reveals that there was no significant association between knowledge and sociodemographic characteristics of the respondents. 
TABLE 1: Sociodemographic characteristics of respondents.

\begin{tabular}{|c|c|c|}
\hline Variable & $\begin{array}{c}\text { Frequency } \\
(n=180)\end{array}$ & Percent \\
\hline \multicolumn{3}{|l|}{ Sex } \\
\hline Male & 95 & 52.8 \\
\hline Female & 85 & 47.2 \\
\hline \multicolumn{3}{|l|}{ Age } \\
\hline$\leq 25$ years & 23 & 12.8 \\
\hline $26-30$ years & 83 & 46.1 \\
\hline $31-35$ years & 48 & 26.7 \\
\hline Above 35 years & 26 & 14.4 \\
\hline \multicolumn{3}{|l|}{ Specialty } \\
\hline Paediatric nurse & 11 & 6.1 \\
\hline General nurse & 148 & 82.2 \\
\hline Critical care nurse & 16 & 8.9 \\
\hline Others & 5 & 2.8 \\
\hline \multicolumn{3}{|l|}{ Level of education } \\
\hline Master's degree & 13 & 7.2 \\
\hline Bachelor's degree & 51 & 28.3 \\
\hline Diploma & 116 & 64.4 \\
\hline \multicolumn{3}{|l|}{ Rank } \\
\hline Staff nurse & 80 & 44.4 \\
\hline Senior staff nurse & 36 & 20.0 \\
\hline Nursing officer & 35 & 19.5 \\
\hline Senior nursing officer & 20 & 11.1 \\
\hline Principal nursing officer & 9 & 5.0 \\
\hline \multicolumn{3}{|c|}{ Working years of experience } \\
\hline$\leq 2$ years & 37 & 20.6 \\
\hline $3-5$ years & 57 & 31.7 \\
\hline$>10$ years & 39 & 21.7 \\
\hline $5-10$ years & 47 & 26.1 \\
\hline \multicolumn{3}{|l|}{ Unit of work } \\
\hline Paediatric ward & 41 & 22.8 \\
\hline Paediatrics emergency & 13 & 7.2 \\
\hline Orthopedics/trauma & 13 & 7.2 \\
\hline General surgery & 40 & 22.0 \\
\hline Theatre recovery & 14 & 7.8 \\
\hline NICU & 31 & 17.2 \\
\hline Neurosurgical ward & 12 & 6.7 \\
\hline Others & 16 & 8.9 \\
\hline \multicolumn{3}{|c|}{ Training on paediatric pain management } \\
\hline Yes & 54 & 30.0 \\
\hline No & 126 & 70.0 \\
\hline \multicolumn{3}{|c|}{ Frequency in caring for children } \\
\hline Never & 8 & 4.4 \\
\hline Often & 53 & 29.5 \\
\hline Occasionally & 58 & 32.2 \\
\hline Always & 61 & 33.9 \\
\hline
\end{tabular}

Source: field data (2019).

3.6. Paediatric Pain Management Practices among Nurses. Most of the respondents (86.1\%) did not use paediatric procedural sedation before carrying out very painful procedures in the hospital. The majority (91.1\%) also indicated that they did not use pain medications during painful procedures while $90.0 \%$ observed the side effects of pain medications after they had given it to children. In the assessment of the child's pain, $77.8 \%$ used a self-reporting pain scale while $78.3 \%$ similarly used a behavioral pain scale. The majority (88.9\%) used several techniques to distract children from pain. Most of the respondents (91.7\%) also reassessed children's pain after pain medication was given to evaluate the effectiveness of pain medication. Most (91.7\%) of the respondents reported that they talked to children in a soft voice to comfort them when they were in pain. Again, the majority of the respondents (78.9\%) asked older children to support the painful areas when moving or coughing. This is shown in Table 4.

With regard to the distribution of pain management practices among nurses in paediatric and nonpaediatric units, the study showed that $56.5 \%$ of respondents who worked in the paediatric wards had practiced good paediatric pain management whereas $59.9 \%$ of those who worked in nonpaediatric wards had good practices on paediatric pain management. This is shown in Figure 3.

\subsection{Summary of Nurses Paediatric Pain Management} Practices. The study again revealed that about $57.8 \%$ and 42 . $2 \%$ of the nurses in this current study engaged in good and poor paediatric pain management practices, respectively, as shown in Figure 4.

3.8. Nurses Paediatric Pain Management Practices according to the Units They Work in. With regard to the distribution of pain management practices among nurses in paediatric and nonpaediatric units, the study showed that nurses who worked in nonpaediatric wards had a higher practice score (59.9\%) than nurses who worked in the paediatric wards $(59.9 \%)$ as shown in Figure 3.

3.9. Factors Associated with Nurses Paediatric Pain Management Practices. Logistic regression analysis revealed that critical care nurses were about 5.87 times more likely to engage in good practices compared to paediatric nurses regarding pain management $\quad(\mathrm{OR}=5.87 \quad(95 \% \quad \mathrm{CI}$ : 1.07-32.00), $p=0.041$ ). Also, bachelor's degree and diploma holders were 10 and 8 times, respectively, more likely to engage in good practices compared to master's degree holders ( $\mathrm{OR}=10.08$ (95\% CI: 2.01-50.57), $p=0.005$, and $\mathrm{OR}=8.07(95 \% \mathrm{CI}: 1.71-38.10), p=0.008)$. This is shown in Table 5.

3.10. Barriers Related to Paediatric Pain Management. From Table 6, the child's uncooperativeness taking medication was the most $(79.4 \%)$ reported barrier related to paediatric pain management, followed by nurses' insufficient knowledge about paediatric pain assessment and management $(76.1 \%)$. The majority $(73.9 \%)$ also reported inadequate paediatric pain assessment tools; $72.2 \%$ reported lack of evidence-based protocol in paediatric pain management in the facility.

\section{Discussion}

The study aimed at evaluating nurses' knowledge, practices, and barriers to paediatric pain management at the largest 
TABLE 2: Knowledge of paediatric pain management among nurses.

\begin{tabular}{|c|c|c|}
\hline Variable & $\begin{array}{l}\text { Frequency } \\
(n=180)\end{array}$ & Percent \\
\hline \multicolumn{3}{|c|}{ Children may sleep in spite of severe pain } \\
\hline Yes & 28 & 15.6 \\
\hline No & 152 & 84.4 \\
\hline \multicolumn{3}{|c|}{$\begin{array}{l}\text { Underdeveloped neurological system makes children under } 2 \text { years of age have decreased pain sensitivity and } \\
\text { limited memory of painful experiences }\end{array}$} \\
\hline Yes & 108 & 60.0 \\
\hline No & 72 & 40.0 \\
\hline \multicolumn{3}{|c|}{ Young infants, less than 6 months of age, cannot tolerate opioids for pain relief } \\
\hline Yes & 107 & 59.4 \\
\hline No & 73 & 40.6 \\
\hline \multicolumn{3}{|c|}{ Vital signs are always reliable indicators of the intensity of a child's pain } \\
\hline Yes & 117 & 65.0 \\
\hline No & 63 & 35.0 \\
\hline \multicolumn{3}{|c|}{ Children who can be distracted usually do not have severe pain } \\
\hline Yes & 62 & 34.4 \\
\hline No & 118 & 65.6 \\
\hline \multicolumn{3}{|c|}{$\begin{array}{l}\text { Children less than } 8 \text { years old cannot reliably report pain so nurses should rely solely on parent's assessment of } \\
\text { the child's pain intensity }\end{array}$} \\
\hline Yes & 73 & 40.6 \\
\hline No & 107 & 59.4 \\
\hline \multicolumn{3}{|c|}{ Intravenous route is the recommended route for administering opioid analgesics in children } \\
\hline Yes & 111 & 61.7 \\
\hline No & 69 & 38.3 \\
\hline \multicolumn{3}{|c|}{$\begin{array}{l}\text { Children with a background of continuous, persistent pain, the oral route is used in the administration of opioid } \\
\text { analgesics }\end{array}$} \\
\hline Yes & 89 & 49.4 \\
\hline No & 91 & 50.6 \\
\hline \multicolumn{3}{|c|}{ Analgesics for postoperative pain should initially be given only when the child asks for the medication } \\
\hline Yes & 24 & 13.3 \\
\hline No & 156 & 86.7 \\
\hline \multicolumn{3}{|c|}{$\begin{array}{l}\text { Behavioral observation scales are the most reliable measures of assessing pain and sedation in intubated/ } \\
\text { ventilated children }\end{array}$} \\
\hline Yes & 126 & 70.0 \\
\hline No & 54 & 30.0 \\
\hline \multicolumn{3}{|c|}{$\begin{array}{l}\text { Opioids should not be used during the pain evaluation period, as this could mask the ability to correctly diagnose } \\
\text { the cause of the pain if the source of the child's pain is unknown }\end{array}$} \\
\hline Yes & 129 & 71.7 \\
\hline No & 51 & 28.3 \\
\hline
\end{tabular}

Source: field data (2019).

tertiary health institution in the northern part of Ghana. The current study was necessary as it will improve nurses' pain management practices with the ultimate aim of improving the quality of paediatric care and care outcomes in the hospital. The majority of nurses in the study did not have any formal training on paediatric pain management. This is in line with a study in Rwanda by Ufashingabire et al. [11] and Zeb et al. [18] in Pakistan where most of the nurses $59.4 \%$ and $83.3 \%$, respectively, had no formal training on paediatric pain management. Having a large number of nurses not having formal training on pain management mostly tends to influence their practice.

In this study, the majority of the nurses demonstrated good knowledge with regard to paediatric pain management. Several studies have corroborated our findings where the majority of the nurses in their respective studies reported good knowledge in paediatric pain management [18-20] in
Bangladesh, the United Kingdom, and Pakistan, respectively. Despite the overall good knowledge score in the current study, the majority of the nurses demonstrated poor knowledge with regard to pain assessment and the use of analgesics in pain management among children. This finding largely agrees with the study by Alotaibi et al. [2] in Australia which revealed that nurses recorded poor knowledge in the areas of basic pain assessment and management principles. Also, the study by Anim-Boamah [16] in the southern part of Ghana revealed that nurses demonstrated limited knowledge about pain assessment scales and pharmacological strategies for managing invasive procedural pain.

Our findings further showed that nurses working in the paediatric units had a high knowledge score (41.2\%) than nurses working at the nonpaediatric (36.8\%). These differences in their knowledge could be due to their frequent 


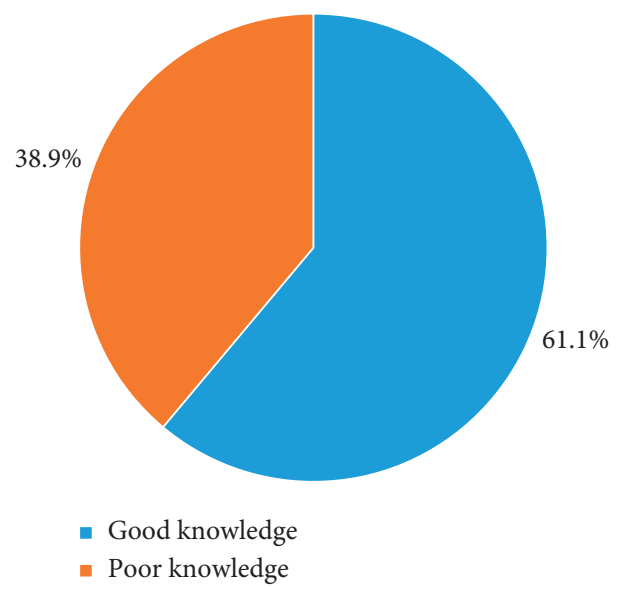

Figure 1: Overall nurses' knowledge on paediatric pain management.

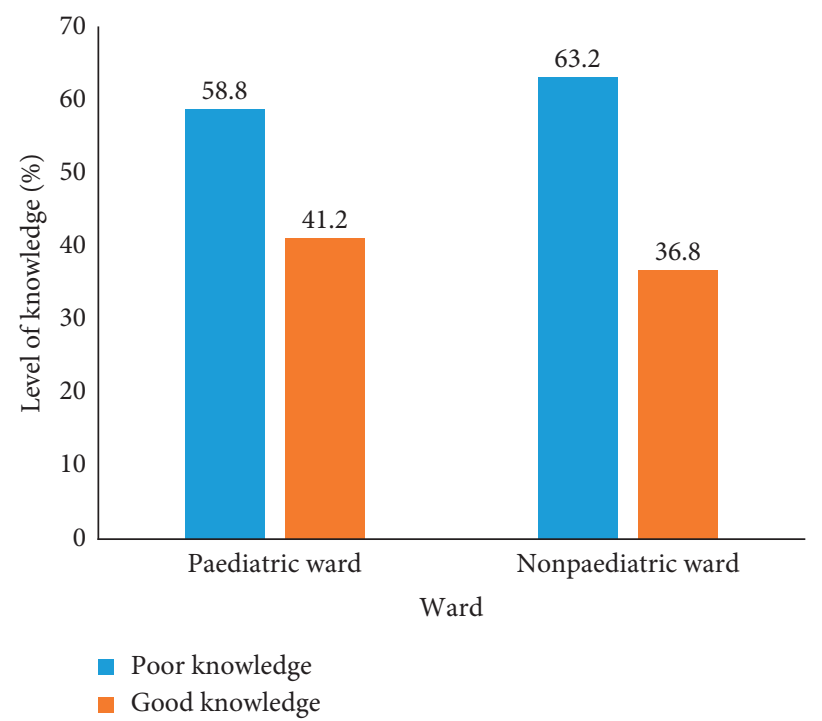

FIGURE 2: Overall level of knowledge on paediatric pain management according to ward type.

exposure to the management of children in the paediatric wards while in the nonpaediatric wards, the management of children is scarce until a child is admitted with a specialized condition. The difference could also be due to the presence of paediatric nurses working in the paediatric wards where a transfer of knowledge could take place among the nurses.

Furthermore, the level of practice with regards to paediatric pain management in our study was generally classified as good. This finding could be attributed to a high number of nurses having good knowledge in the area. The current finding is in line with a study by Miftah et al. [21] in Ethiopia which showed that $55.8 \%$ of nurses who were involved in the study had good practices of paediatric pain management. It is however worth noting that nurses who worked in nonpaediatric wards could manage paediatric pain than those working in paediatric wards despite their high knowledge level.

Items analysis from our study showed that the majority of the nurses who were involved in the study used a selfreporting pain scale and behavioral pain scale in their pain management practices. This is corroborated with studies by Hossain et al. [19] and Baulch [22] where most nurses who took part in the study used self-reporting pain scale and behavioral pain scale in their pain management practices.

Concerning the barriers to paediatric pain management among the nurses, the majority of the nurses reported a child's uncooperativeness during pain medication administration (79.4\%) and insufficient knowledge about paediatric pain assessment and management $(76.1 \%)$ by nurses as the most reported barriers related to paediatric pain management. The findings of $[7,23]$ in Canada and the United States of America, respectively, reported similar findings. Furthermore, $73.9 \%$ of nurses in the current study also reported inadequate paediatric pain assessment tools as barrier to paediatric pain management. The findings of Kahsay and Pitkäjärvi [24] in Finland corroborate our findings where they revealed lack of protocols for pain assessment and lack of pain assessment tools to be the most perceived barriers to paediatric pain management. 
TABLE 3: Association between knowledge and sociodemographic characteristics.

\begin{tabular}{|c|c|c|c|c|c|}
\hline \multirow[b]{2}{*}{ Variable } & \multicolumn{2}{|c|}{ Knowledge level } & \multirow[b]{2}{*}{$x^{2}$} & \multirow[b]{2}{*}{$p$ value } & \multirow[b]{2}{*}{ OR (95\% CI), $p$ value } \\
\hline & $\begin{array}{c}\text { Poor knowledge } n=110 \\
(\%)\end{array}$ & $\begin{array}{c}\text { Good knowledge } n=70 \\
(\%)\end{array}$ & & & \\
\hline \multicolumn{6}{|c|}{ 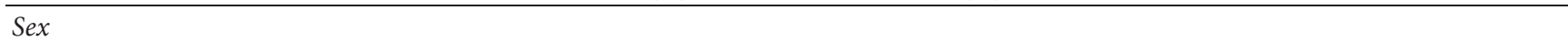 } \\
\hline Male & $55(50.0)$ & $40(57.1)$ & & & \\
\hline Female & $55(50.0)$ & $30(42.9)$ & 0.88 & 0.349 & $0.75[0.41-1.37], 0.350$ \\
\hline \multicolumn{6}{|l|}{ Age of respondents } \\
\hline$\leq 25$ years & $15(13.6)$ & $8(11.4)$ & & & \\
\hline $26-30$ years & $50(45.5)$ & $33(47.2)$ & & & $1.24[0.47-3.25], 0.665$ \\
\hline $31-35$ years & $29(26.4)$ & $19(27.1)$ & & & $1.23[0.44-3.46], 0.697$ \\
\hline Above 35 years & $16(14.5)$ & $10(14.3)$ & 0.20 & 0.977 & $1.17[0.37-3.76], 0.790$ \\
\hline \multicolumn{6}{|l|}{ Specialty } \\
\hline Paediatric nurse & $6(5.5)$ & $5(7.1)$ & & & \multirow{4}{*}{$\begin{array}{c}0.75[0.22-2.58], 0.650 \\
0.55[0.11-2.67], 0.455 \\
1.80[0.21-15.41], \\
0.592\end{array}$} \\
\hline General nurse & $91(82.7)$ & $57(81.5)$ & & & \\
\hline Critical care nurse & $11(10.0)$ & $5(7.1)$ & & & \\
\hline Others & $2(1.8)$ & $3(4.3)$ & 1.54 & 0.673 & \\
\hline \multicolumn{6}{|l|}{ Level of education } \\
\hline Master's degree & $10(9.1)$ & $3(4.3)$ & & & \multirow[b]{2}{*}{$\begin{array}{c}2.53[0.62-10.30] \\
0.195\end{array}$} \\
\hline Bachelor's degree & $29(26.4)$ & $22(31.4)$ & & & \\
\hline Diploma & $71(64.5)$ & $45(64.3)$ & 1.76 & 0.416 & $2.11[0.55-8.09], 0.275$ \\
\hline \multicolumn{6}{|l|}{ Rank } \\
\hline Staff nurse & $51(46.4)$ & $29(41.4)$ & & & \\
\hline Senior staff nurse & $19(17.3)$ & $17(24.3)$ & & & 1.57 [0.71-3.49], 0.265 \\
\hline Nursing officer & $19(17.3)$ & $16(22.9)$ & & & $1.48[0.66-3.20], 0.340$ \\
\hline Senior nursing officer & $15(13.6)$ & $5(7.1)$ & & & 0.59 [0.19-1.78], 0.346 \\
\hline Principal nursing officer & $6(5.4)$ & $3(4.3)$ & 3.71 & 0.446 & $0.88[0.20-3.78], 0.863$ \\
\hline \multicolumn{6}{|l|}{ Years of work experience } \\
\hline$\leq 2$ years & $22(20.0)$ & $15(21.4)$ & & & \\
\hline $3-5$ years & $37(33.6)$ & $20(28.6)$ & & & $0.79[0.34-1.86], 0.593$ \\
\hline$>10$ years & $23(20.9)$ & $16(22.9)$ & & & $1.02[0.41-2.55], 0.966$ \\
\hline $5-10$ years & $28(25.5)$ & $19(27.1)$ & 0.51 & 0.917 & 0.99 [0.41-2.39], 0.991 \\
\hline \multicolumn{6}{|l|}{ Unit of work } \\
\hline Paediatrics & $22(20.0)$ & $19(27.1)$ & & & \\
\hline Paediatrics emergency & $10(9.1)$ & $3(4.3)$ & & & $0.35[0.08-1.45], 0.147$ \\
\hline Orthopedics/trauma & $11(10.0)$ & $2(2.9)$ & & & $0.21[0.04-1.07], 0.060$ \\
\hline General surgery & $29(26.4)$ & $19(27.1)$ & & & $0.76[0.33-1.76], 0.521$ \\
\hline Theatre recovery & $10(9.1)$ & $4(5.7)$ & & & $0.46[0.12-1.72], 0.250$ \\
\hline NICU & $18(16.4)$ & $13(18.6)$ & & & $0.84[0.33-2.14], 0.710$ \\
\hline Other surgeries & $5(4.5)$ & $7(10.0)$ & & & $1.62[0.44-5.96], 0.467$ \\
\hline Others & $5(4.5)$ & $3(4.3)$ & 8.02 & 0.331 & $0.69[0.15-3.30], 0.647$ \\
\hline \multicolumn{6}{|c|}{$\begin{array}{l}\text { Formal training on paediatric pain } \\
\text { management }\end{array}$} \\
\hline Yes & $29(26.4)$ & $25(35.7)$ & & & \\
\hline No & $81(73.6)$ & $45(64.3)$ & 1.78 & 0.182 & $0.64[0.34-1.23], 0.183$ \\
\hline
\end{tabular}

Source: field data (2019).

Contrary to our findings on the barriers, Katende and Mugabi [25] in Uganda identified lack of time (42\%), having emergencies (18\%), and not knowing the right method to use (11\%) as the most occurring barriers to paediatric pain management. Findings from Kusi Amponsah et al. [3] in Ghana which also disagrees with our study further reported communication difficulties in assessing and evaluating pain management interventions with children who have nonfunctional speech, misconceptions on the experience of pain in children, and an insufficient number of nurses to manage the workload and nurses' inability to prescribe analgesics as the major barriers to paediatric pain management. 
TABLE 4: Paediatric pain management practices.

\begin{tabular}{|c|c|c|}
\hline Variable & Frequency $(n=180)$ & Percent \\
\hline $\begin{array}{l}\text { Use of policy in hospital for paediatric procedural sedation } \\
\text { Yes } \\
\text { No }\end{array}$ & $\begin{array}{c}25 \\
155 \\
\end{array}$ & $\begin{array}{l}13.9 \\
86.1 \\
\end{array}$ \\
\hline $\begin{array}{l}\text { Use of pain medications/sedation during painful procedure } \\
\text { Yes } \\
\text { No }\end{array}$ & $\begin{array}{c}16 \\
164 \\
\end{array}$ & $\begin{array}{r}8.9 \\
91.1 \\
\end{array}$ \\
\hline $\begin{array}{l}\text { Observation of side effects of pain medication after giving it to children } \\
\text { Yes } \\
\text { No }\end{array}$ & $\begin{array}{c}162 \\
18 \\
\end{array}$ & $\begin{array}{l}90.0 \\
10.0 \\
\end{array}$ \\
\hline $\begin{array}{l}\text { Placing of children in comfortable positions to help relieve pain } \\
\text { Yes } \\
\text { No }\end{array}$ & $\begin{array}{c}172 \\
8 \\
\end{array}$ & $\begin{array}{c}95.6 \\
4.4 \\
\end{array}$ \\
\hline $\begin{array}{l}\text { Use of self-reporting pain scale to assess children's pain } \\
\text { Yes } \\
\text { No }\end{array}$ & $\begin{array}{c}140 \\
40\end{array}$ & $\begin{array}{l}77.8 \\
22.2 \\
\end{array}$ \\
\hline $\begin{array}{l}\text { Use of behavioral pain scale to assess children's pain } \\
\text { Yes } \\
\text { No }\end{array}$ & $\begin{array}{c}141 \\
39\end{array}$ & $\begin{array}{l}78.3 \\
21.7 \\
\end{array}$ \\
\hline $\begin{array}{l}\text { Use of several techniques to distract children from pain } \\
\text { Yes } \\
\text { No }\end{array}$ & $\begin{array}{c}160 \\
20 \\
\end{array}$ & $\begin{array}{l}88.9 \\
11.1 \\
\end{array}$ \\
\hline $\begin{array}{l}\text { Reassessing children's pain after given pain medication to evaluate the effectiveness of pain medication } \\
\text { Yes } \\
\text { No }\end{array}$ & $\begin{array}{c}165 \\
15 \\
\end{array}$ & $\begin{array}{c}91.7 \\
8.3 \\
\end{array}$ \\
\hline $\begin{array}{l}\text { Administration of additional pain medication to relieve pain when needed } \\
\text { Yes } \\
\text { No }\end{array}$ & $\begin{array}{c}170 \\
10 \\
\end{array}$ & $\begin{array}{c}94.4 \\
5.6 \\
\end{array}$ \\
\hline $\begin{array}{l}\text { Talking to children with a soft voice to comfort them when they are in pain } \\
\text { Yes } \\
\text { No }\end{array}$ & $\begin{array}{c}165 \\
15 \\
\end{array}$ & $\begin{array}{c}91.7 \\
8.3 \\
\end{array}$ \\
\hline $\begin{array}{l}\text { Asking and helping children to support the painful areas when moving or coughing } \\
\text { Yes } \\
\text { No }\end{array}$ & $\begin{array}{c}142 \\
38\end{array}$ & $\begin{array}{l}78.9 \\
21.1\end{array}$ \\
\hline
\end{tabular}

Source: field data (2019).

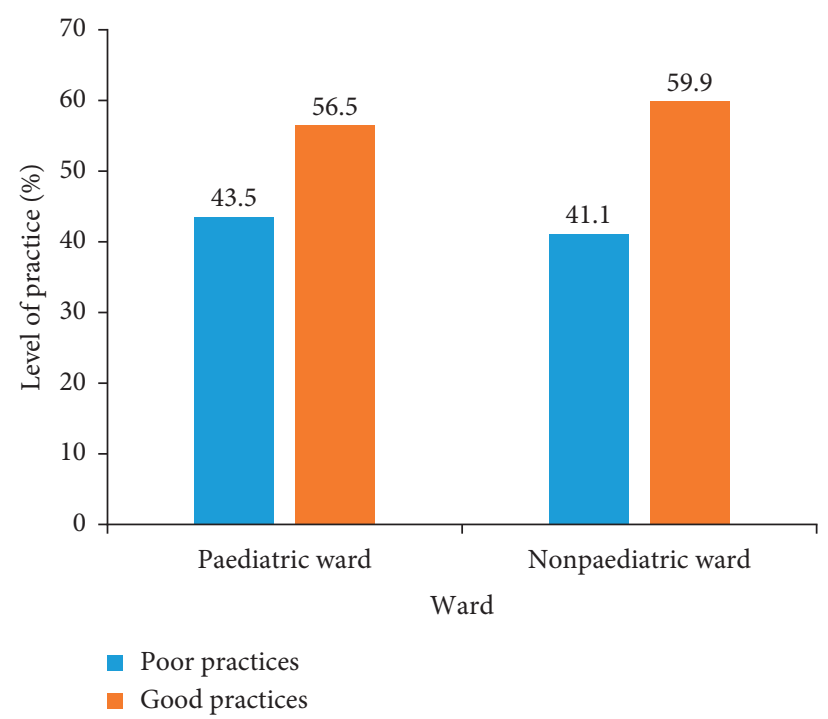

FIGURE 3: Overall level of practices on paediatric pain management according to ward type. Source: field data (2019). 


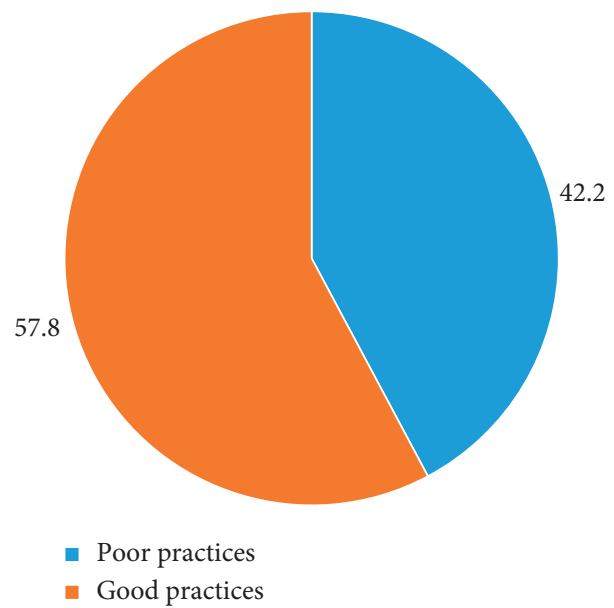

Figure 4: Overall level of practices on paediatric pain management. Source: field data (2019).

TABLE 5: Logistic regression results showing factors associated with nurses' paediatric pain management practices.

\begin{tabular}{|c|c|c|c|c|c|}
\hline \multirow{2}{*}{ Variable } & \multicolumn{2}{|c|}{ Practices level } & \multirow{2}{*}{$x^{2}$} & \multirow{2}{*}{$p$ value } & \multirow{2}{*}{ OR $(95 \% \mathrm{CI}), p$ value } \\
\hline & Poor practices $n=76(\%)$ & Good practices $n=104(\%)$ & & & \\
\hline \multicolumn{6}{|l|}{ Sex } \\
\hline Male & $42(55.3)$ & $53(51.0)$ & & & \\
\hline Female & $34(44.7)$ & $51(49.0)$ & 0.33 & 0.568 & $1.19[0.66-2.15], 0.568$ \\
\hline \multicolumn{6}{|l|}{ Age group } \\
\hline$\leq 25$ years & $11(14.5)$ & $12(11.5)$ & & & \\
\hline $26-30$ years & $28(36.8)$ & $55(52.9)$ & & & $1.80[0.71-4.59], 0.218$ \\
\hline $31-35$ years & $24(31.6)$ & $24(23.1)$ & & & $0.92[0.34-2.48], 0.864$ \\
\hline Above 35 years & $13(17.1)$ & $13(12.5)$ & 4.58 & 0.205 & $0.92[0.29-2.82], 0.879$ \\
\hline \multicolumn{6}{|l|}{ Specialty } \\
\hline Paediatric nurse & $8(10.5)$ & $3(2.9)$ & & & \\
\hline General nurse & $61(80.3)$ & $87(83.6)$ & & & 3.80 [0.97-14.92], 0.055 \\
\hline Critical care nurse & $5(6.6)$ & $11(10.6)$ & & & $5.87[1.07-32.00], 0.041$ \\
\hline Others & $2(2.6)$ & $3(2.9)$ & 5.06 & 0.168 & $4.00[0.43-37.12], 0.223$ \\
\hline \multicolumn{6}{|l|}{ Level of education } \\
\hline Master's degree & $11(14.5)$ & $2(1.9)$ & & & \\
\hline Bachelor's degree & $18(23.7)$ & $33(31.7)$ & & & 10.08 [2.01-50.57], 0.005 \\
\hline Diploma & $47(61.8)$ & $69(66.4)$ & 10.72 & 0.005 & $8.07[1.71-38.10], 0.008$ \\
\hline \multicolumn{6}{|l|}{ Rank } \\
\hline Staff nurse & $35(46.0)$ & $45(43.3)$ & & & \\
\hline Senior staff nurse & $12(15.8)$ & $24(23.1)$ & & & $1.56[0.68-3.54], 0.292$ \\
\hline Nursing officer & $10(13.2)$ & $25(24.0)$ & & & $1.94[0.83-4.58], 0.128$ \\
\hline Senior nursing officer & $12(15.8)$ & $8(7.7)$ & & & $0.52[0.19-1.41], 0.197$ \\
\hline Principal nursing officer & $7(9.2)$ & $2(1.9)$ & 11.17 & 0.025 & $0.22[0.04-21.14], 0.071$ \\
\hline \multicolumn{6}{|l|}{ Years of work experience } \\
\hline$\leq 2$ years & $12(15.8)$ & $25(24.0)$ & & & \\
\hline $3-5$ years & $30(39.5)$ & $27(26.0)$ & & & $0.43[0.18-1.02], 0.057$ \\
\hline$>10$ years & $16(21.0)$ & $23(22.1)$ & & & $0.69[0.27-1.76], 0.438$ \\
\hline $5-10$ years & $18(23.7)$ & $29(27.9)$ & 4.31 & 0.230 & $0.77[0.31-1.91], 0.578$ \\
\hline \multicolumn{6}{|l|}{ Unit of work } \\
\hline Paediatrics & $20(26.3)$ & $21(20.2)$ & & & \\
\hline Paediatrics emergency & $4(5.3)$ & $9(8.7)$ & & & $2.14[0.57-8.08], 0.260$ \\
\hline Orthopedics/trauma & $5(6.6)$ & $8(7.7)$ & & & $1.52[0.43-5.45], 0.517$ \\
\hline General surgery & $22(29.0)$ & $26(25.0)$ & & & $1.13[0.49-2.59], 0.781$ \\
\hline Theatre recovery & $6(7.9)$ & $8(7.7)$ & & & $1.27[0.37-4.31], 0.702$ \\
\hline NICU & $13(17.1)$ & $18(17.3)$ & & & $1.32[0.36-3.38], 0.564$ \\
\hline Other surgeries & $5(6.6)$ & $7(6.7)$ & & & $1.33[0.36-4.89], 0.665$ \\
\hline Others & $1(1.3)$ & $7(6.7)$ & 4.66 & 0.702 & $6.67[0.75-59.15], 0.089$ \\
\hline \multicolumn{6}{|c|}{ Formal training on paediatric pain management } \\
\hline Yes & $22(28.9)$ & $32(30.8)$ & & & \\
\hline No & $54(71.1)$ & $72(69.2)$ & 0.07 & 0.792 & $0.92[0.48-1.75], 0.792$ \\
\hline
\end{tabular}


TABLE 6: Barriers related to paediatric pain management.

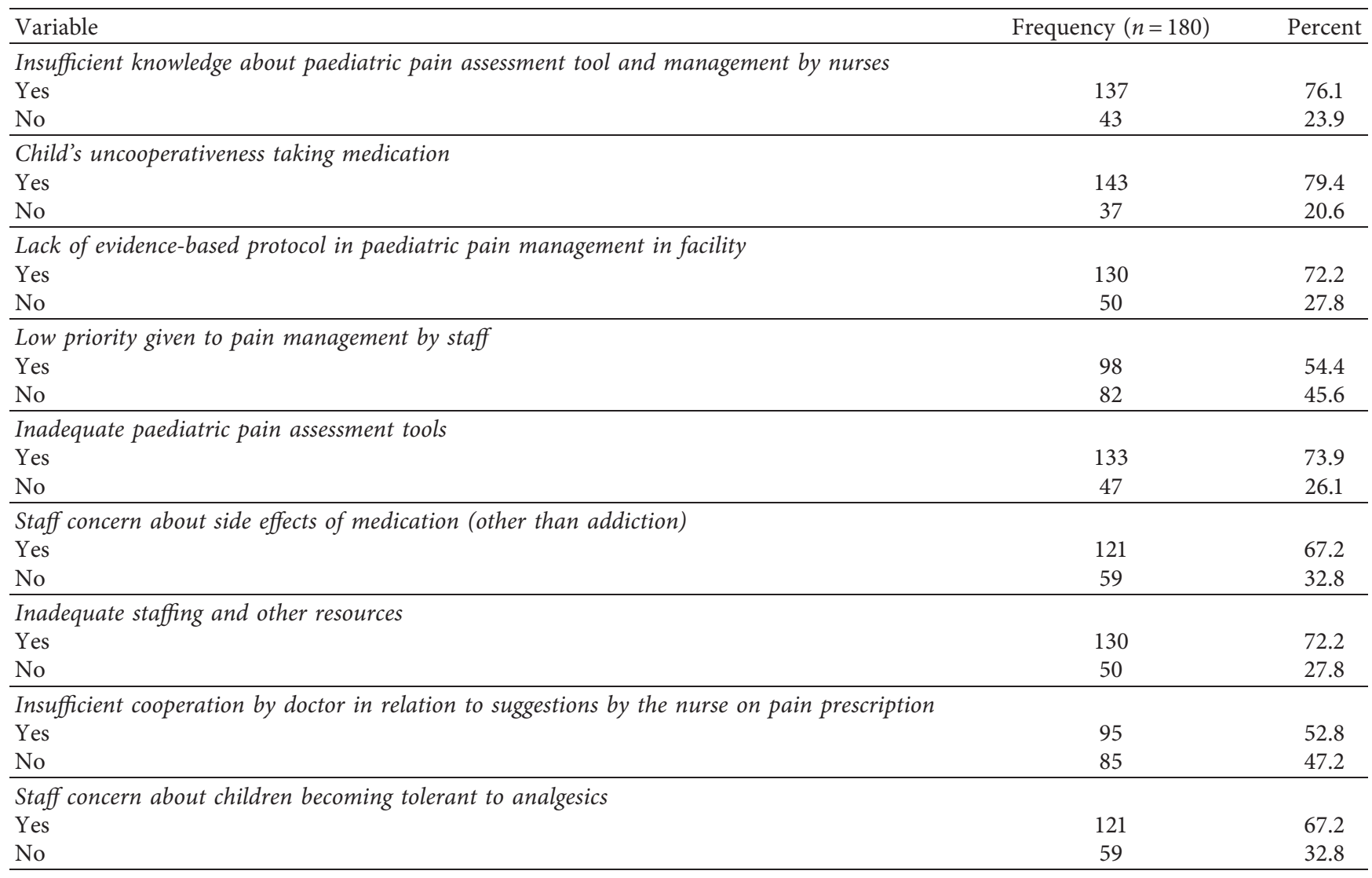

Source: field data (2019).

\section{Conclusion}

The current study reported an overall good knowledge and practice of nurses regarding paediatric pain management. Also, nurses who worked in paediatric wards demonstrated high knowledge while those who work in nonpaediatric wards demonstrated good practice despite the majority not receiving formal training on pain management. Though some of the nurses had good knowledge and practices, there is still the need to organize regular in-service training for both nurses in paediatric and nonpaediatric units on paediatric pain management to ensure that they are up to date with the current trend in paediatric pain management. Paediatric pain management should be treated as a priority and hence more efforts should be put in place to curtail the barriers especially those related to inadequate knowledge, human, and material resources.

\section{Data Availability}

The data used for this study were collected from Tamale Teaching Hospital and are available on request from the corresponding author.

\section{Disclosure}

This study was limited to only nurses in one tertiary health facility and therefore lacking generalizability to other clinical professionals.

\section{Conflicts of Interest}

The authors declare no conflicts of interest.

\section{Authors' Contributions}

All the authors contributed to the conception and design of the study and approved the final manuscript for submission.

\section{Acknowledgments}

The authors express their sincere appreciation to all the staff of the Paediatric Department of Tamale Teaching Hospital, most especially Peter Tonlaar, Hannah Buasilenu, and Asana Fuseini for their support. Their thanks are also due to all the nurses who willingly participated in the study.

\section{References}

[1] A. Taddio, C. T. Chambers, S. A. Halperin et al., "Inadequate pain management during routine childhood immunizations: the nerve of it," Clinical Therapeutics, vol. 31, no. SUPPL. 2, pp. S152-S167, 2009.

[2] K. Alotaibi, I. Higgins, J. Day, and S. Chan, "Paediatric pain management: knowledge, attitudes, barriers and facilitators among nurses-integrative review," International Nursing Review, vol. 65, no. 4, pp. 524-533, 2018.

[3] A. Kusi Amponsah, E. F. Kyei, J. B. Agyemang et al., "Nursingrelated barriers to children's pain management at selected 
hospitals in Ghana: a descriptive qualitative study," Pain Research and Management, vol. 2020, Article ID 7125060, , 2020.

[4] A. Ekim and A. F. Ocakc1, "Knowledge and attitudes regarding pain management of pediatric nurses in turkey," Pain Management Nursing, vol. 14, no. 4, pp. e262-e267, 2013.

[5] A. Hiller and P. K. Suominen, "Pain in children is still underrecognized and undertreated in Scandinavia," Acta Anaesthesiologica Scandinavica, vol. 61, no. 3, pp. 266-267, 2017.

[6] L. Vagnoli, M. Mammucari, D. Graziani, and A. Messeri, "Doctors and nurses' knowledge and attitudes towards pediatric pain management: an exploratory survey in a children's hospital," Journal of Pain \& Palliative Care Pharmacotherapy, vol. 33, no. 3-4, pp. 107-119, 2019.

[7] M. M. Ortiz, E. Carr, and A. Dikareva, "An integrative review of the literature on pain management barriers: implications for the Canadian clinical context," Canadian Journal of Nursing Research, vol. 46, no. 3, pp. 65-93, 2014.

[8] A. Twycross, P. Forgeron, and A. Williams, "Paediatric nurses' postoperative pain management practices in hospital based non-critical care settings: a narrative review," International Journal of Nursing Studies, vol. 52, no. 4, pp. 836-863, 2015.

[9] S. Walther-Larsen, M. T. Pedersen, S. M. Friis et al., "Pain prevalence in hospitalized children: a prospective cross-sectional survey in four Danish university hospitals," Acta Anaesthesiologica Scandinavica, vol. 61, no. 3, pp. 328-337, 2017.

[10] K. Nuseir, M. Kassab, and B. Almomani, "Healthcare providers' knowledge and current practice of pain assessment and management: how much progress have we made?" Pain Research and Management, vol. 2016, Article ID 8432973, 7 pages, 2016.

[11] C. M. Ufashingabire, E. Nsereko, K. J. Njunwa, and P. Brysiewicz, "Knowledge and attitudes of nurses regarding pain in the intensive care unit patients in Rwanda," Rwanda Journal, vol. 3, no. 1, pp. 21-26, 2016.

[12] P. Aranha and U. Jayaraman, "Assessment and management of pain in children: knowledge and attitude of staff nurses assessment and management of pain in children," 2015.

[13] L. Aziato and O. Adejumo, "Determinants of nurses' knowledge gap on pain management in Ghana," Nurse Education in Practice, vol. 14, no. 2, pp. 195-199, 2014.

[14] M. L. Czarnecki, K. Simon, J. J. Thompson et al., "Do barriers to pediatric pain management as perceived by nurses change over time?" Pain Management Nursing, vol. 15, no. 3, pp. 292-305, 2014.

[15] A. Twycross and S. Collins, "Nurses' views about the barriers and facilitators to effective management of pediatric pain," Pain Management Nursing, vol. 14, no. 4, pp. e164-e172, 2013.

[16] O. Anim-Boamah, "NURSES' perspectives ON invasive procedural pain among paediatric patients at the regional hospital, Koforidua," 2015, http://ugspace.ug.edu.gh.

[17] T. Yammane, "An introductory analysis," Harper and Row, New York, NY, USA, 2nd edition, 1967.

[18] A. Zeb, J. M. Farhana, and U. Nadra Bi Bi, "Nurses knowledge regarding post-operative pain management," Journal of Healthcare Communications, vol. 4, no. 1, pp. 4-7, 2019.

[19] S. Hossain, W. Wiroonpanich, and R. Orapiriyakul, "Nurses' knowledge and attitudes in pain management practice of postoperative children in Bangladesh," in Proceedings of the 2nd International Conference on Humanities and Social Sciences, pp. 1-12, Rome, Italy, Sepetember 2010.
[20] A. O. Akuma and S. Jordan, "Pain management in neonates: a survey of nurses and doctors," Journal of Advanced Nursing, vol. 68, no. 6, pp. 1288-1301, 2012.

[21] R. Miftah, W. Tilahun, A. Fantahun, S. Adulkadir, and K. Gebrekirstos, "Knowledge and factors associated with pain management for hospitalized children among nurses working in public hospitals in Mekelle City, North Ethiopia: cross sectional study," BMC Research Notes, vol. 10, no. 1, pp. 2-7, 2017.

[22] I. Baulch, "Assessment and management of pain in the paediatric patient," Nursing Standard, vol. 25, no. 10, pp. 35-40, 2010.

[23] C. V. H. Vincent, "Nurses' knowledge, attitudes, and practices regarding children's pain," MCN The American Journal of Maternal/Child Nursing, vol. 30, no. 3, pp. 177-183, 2005.

[24] D. T. Kahsay and M. Pitkäjärvi, "Emergency nurses' knowledge, attitude and perceived barriers regarding pain management in resource-limited settings: cross-sectional study," 2019.

[25] G. Katende and B. Mugabi, "Comforting strategies and perceived barriers to pediatric pain management during IV line insertion procedure in Uganda's national referral hospital: a descriptive study," BMC Pediatrics, vol. 15, no. 1, pp. 1-8, 2015. 